\section{DOCUMENTAÇÃOPARAA HISTÓRIA DA IGREJA}

\title{
ESCRAVIDÃO, FEITIÇARIA E IGREJA NO SÉCULO XVIII
}

\author{
Os Processos do Arquivo da Cúria \\ Metropolitana de São Paulo
}

Pe. Antônio Raimundo Pereira de Jesus

\section{$\mathbf{N}$ To s} culo XVIII, seguindo o costume vigente desde séculos anteriores, tanto a Igreja como o Estado proibiam as práticas religiosas que não estivessem de acordo com a doutrina ensinada pela Igreja. Sendo a escravidão o grande pano de fundo do universo colonial e esforçando-se as populações africanas para sobreviver física e culturalmente num mundo alheio, foi comum que as acusações de feitiçaria e práticas diabólicas tomassem como alvo os negros e escravos. Contudo, no cotidiano do Brasil-Colônia, não faltaram brancos e senhores sendo acusados e perseguidos por reconrerem à feitiçaria.

\section{Considerada um crime que per-} tencia a ousada da Inquisição, a feitiçaria é comum na documentação inquisitorial arquivada em Portugal. Porém, pela presença no dia a dia de práticas proibidas pela Igreja, os registros eclesiásticos brasileiros passaram a conviver com esta realidade.

O Arquivo da Cúria Metropolitana de São Paulo conserva em seu interior centenas de processos, que dizem respeito a crimes considerados da ousada da Igreja. Entre estes, têm sido localizados para o século XVIII, dez processos referentes à feitiçaria. Eles constituem a matéria do seguinte trabalho.

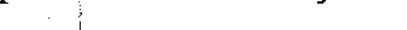


Os processos eclesiásticos, regidos pelo Direito Canônico, proporcionavam no período colonial o espaço para administração da justiça eclesiástica, decidindo-se neles respeito às transgressões $\mathrm{e}$ crimes cometidos contra a doutrina e as normas da Igreja, por eclesiásticos, fiéis e mesmo pessoas de fora da religião católica. O processo visava estabelecer a existência ou não da falta, a culpa do transgressor e a punição do mesmo. Esperava-se também que dele surgisse a recuperação do faltoso e a tranqüilização da comunidade. Assim, o Regimento do Auditório Eclesiástico da Bahia encabeça da seguinte forma o edital das visitações destinadas a corrigir os abusos:

"O N. Visitador neste Arce. bispado da Bahia pelo Ilustrís. simo e Reverendíssimo Senhor D. N. Arcebispo deste Arcebispado, do Conselho de S. Majestade. A todas as pessoas Eclesiásticas, $e$ seculares desta Comarca de N. saúde em JESUS Cristo nosso Redentor... mando em virtude da obediência, e sobre pena de excomunhão maior a todas $e$ a cada uma das sobreditas pessoas, que souberam de certa sabedoria, ou fama pública de alguns pecados públicos, e escandalosos, e nos casos especiais que abaixo se declaram, ainda que não sejam públicos, em termo de N. mo venham a dizer, e denunciar."1

Para o Brasil, junto com a doutrina da Igreja e a piedade dos missionários e colonizadores portugueses, vieram práticas e crenças profundamente arraigadas na $\mathrm{Pe}$ nínsula Ibérica. Também os sacerdotes que passaram para a colônia nos primeiros anos não gozavam de uma sólida preparação, dificultando ainda mais a distinção entre práticas religiosas certas e erradas. Assim para Sônia Siqueira, estudiosa da inquisição portuguesa, não causou estranheza que "na colonia os padres igno. rassem a ordem das pessoas da Santíssima Trindade, a maneira certa de se persignar, não soubessem se Cristo ressuscitaria ou não."

Identificado com o inferno nas crônicas portuguesas, o Brasil foi

1. D. Sebastião Monteiro de Vide, Constituições do Arcebispado da Bahia, São Paulo, Typographia 2 de dezembro, 1853, (Regimento do Auditório Eclesiástico), Título VIII, parágrafo 398 , p. 87. 2. Sônia Siqueira. A Inquisição Portuguesa e a Sociedade Colonial, São Paulo, Ática, 1978,
p. 87.

visto como o reino da superstição indígena e a feitiçaria africana. Assim, "os portugueses chegaram ao Brasil num momento em que a presença de Satã entre os homens era especialmente marcante. Monstros, animais, seres diabólicos, os colonos foram também feiticeiros... Índios $d a$ América, negros da África e brancos da Europa se combinaram mais uma vez para engendrar práticas mágicas e de feiticaria extremamente complexas e originais."

Instaurado o "desvio", não demorou muito também em instalarse sua repressão. Como era de se esperar num século XVI atravessado pela atuação da Inquisição na Espanha e em Portugal. Foram várias as visitas do Santo Ofício ao Brasil durante os séculos XVI, XVII e XVIII. "Bahia, Pernambuco, Paraiba, Grão-Pará, Maranhão, Minas Gerais e Rio de Janeiro. Excetuando as duas últimas áreas todas as demais tiveram a Visitação do Santo Oficio."

No Rio de Janeiro, nas Minas Gerais e mesmo no distante Mato Grosso, através dos "seus familiares" e de outras denúncias o Santo Ofício também se fez presente.

\section{III}

No Brasil colonial a palavra feitiçaria era utilizada para desclassificar e criminalizar práticas que não tinham o reconhecimento oficial da Igreja outorgado a devoções e atos de piedade. As Constituições da Bahia entendiam desta forma que "fazer pacto com o Demônio contém em si grave malícia, assim pela inimizade, que Deus no princípio do mundo pôs entre ele $e$ os homens... Por tanto, ordenamos e mandamos que o que fizer pacto com o Demônio, ou invocar para qualquer $e^{-}$ feito que seja, ou usar de feitiçaria para o mal ou para o bem, principalmente se ofizer com pedras de Ara, Corporaes, e cousas sagradas, ou bentas, a fim de legar, ou delegar, conceber, mover, ou parir, ou para quaisquer outros efeitos bons, ou maus, incorrerá em excomunhão."5

Mesmo com a existência das leis que condenavam pacto com o Demônio ou as práticas de feitiçarias, elas passaram a ser algo cotidiano no Brasil. Índios, negros e brancos, tinham o costume de receitarem remédios caseiros, observar as

3. Laura de Mello e Souza. O Diabo e a Terra da Santa Cruz, Companhia das Letras, 1989, $2^{\mathrm{a}}$ edição, p. 153 , São Paulo.

4. Ibid., p. 18.

5. D. Sebastião Monteiro de Vide, op. cit., Livro Quinto, parágrafo 896, p. 314. 
mudanças dos tempos por meio dos astros, entrar em transe, fazer orações para conseguirem curas, etc..

Por fazer remédios caseiros, rezar para aliviar as dores dos doentes e tentar curar aos mordidos por cobras, Patrício Bicudo da Silva foi denunciado por seu patrão em 1749. Homem estimado por grande parte dos depoentes, no processo era visto pelos vizinhos como alguém que não deixava de ajudar a quem dele precisava. Alegações que não foram suficientes para evitar sua condenação. Também por supor que Pascoal José de Moura, residente em Porto Feliz, interior de São Paulo, sabia fazer "orações para se livrar de inimigos" ${ }^{\prime}$, seus vizinhos o denunciaram em 1765 pela prática de feitiçaria. A feitiçaria, assim, era descoberta nas mais variadas apresentações de um povo que pelas suas raízes portuguesas, indígenas e africanas não poderia ter nunca a ortodoxia cristã proclamada em Trento.

\section{III}

Expressando a vontade de combater os erros e desvios em relação à fé e à prática religiosa, as
Constituições Primeiras do Arcebispado da Bahia, mandavam que todas as pessoas suspeitas de praticarem qualquer tipo de feitiçaria deveriam ser denunciadas às autoridades competentes para que se pudessem fazer as investigações. ${ }^{7}$ Para as visitas pastorais (também regulamentadas pelas próprias Constituições) qualquer pessoa que soubesse de um delito ou crime contra a Doutrina Cristã e a Igreja, deveria fazer a denúncia ante o visitador sem que fosse necessário apresentar provas concretas, bastando uma leve suspeita. ${ }^{8}$

No cotidiano da colônia, esta denúncia só fundamentada na mais simples suspeita, passou a escudarse na expressão "ouvir dizer" que deixava o denunciante livre de apresentar provas. Por "ouvir dizer", Pascoa, escrava de Maria Serqueira, foi denunciada em São Paulo, em 1749, por fazer feitiçaria para matar gente. A denunciante, irmã de uma das supostas vítimas, teria "ouvido dizer" que Pascoa tinha matado com feitiçaria uma senhora de nome Ana e mais duas pessoas, Manoel e Jorge Lopés. Corrido o processo, Pas-

6. ACMSP, Arquivo da Cúria Metropolitana de São Paulo, Processo de Oraçôes Contrai os Inimigos, 1765.

7. D. Sebastião Monteiro de Vide, op. cit., Livro Quinto, parágrafo 866, p. 311.

8. Ibid., Regimento do Auditório Eclesiástico, parágrafo 398, p. 87.

coa foi achada culpada e condenada. ${ }^{9}$

Aproveitando-se destas facilidades passou a ser comum no Brasil, as pessoas utilizarem a denúncia ante as autoridades eclesiásticas para resolverem problemas e conflitos internos, mesmo entre amigos e parentes. "Denúncias de feitiçaria freqüentemente refletiam tensões existentes entre vizinhos, conhecidos e amigos", acredita Laura de Mello e Souza, que tem feito extensas pesquisas nos arquivos inquisitoriais. ${ }^{10}$

Num universo atravessado pela escravidão e a discriminação de índios e mestiços, como o Brasil colonial, a acusação de feitiçaria era utilizada como uma forma de desclassificar a indivíduos e grupos enxergados como perigosos, como era o caso dos escravos e libertos. Ainda assim, como acredita Laura de Mello e Souza "to" das as camadas sociais se viam às voltas com estes tipos de práticas, sendo sujeito e objeto delas." "Desta forma os processos existentes no arquivo, mostram a extensão social das práticas consi- deradas como feitiçaria, presentes em todos os grupos sociais coloniais. Inácio de Siqueira e sua filha Maria, brancos pertencentes a uma família de origem portuguesa, foram acusados em 1772 de usarem santos católicos para pedirem esmolas fazendo danças e batuques ilícitos. ${ }^{12}$ Outro branco, Manoel da Silva Carrier, que morava em Taubaté, também acusado por feitiçaria, foi condenado em 1759 à prisão por usar mandingas para conquistar mulheres $\mathrm{e}$ ganhar em jogos..$^{13}$

Porém, se a denúncia de feitiçaria chegou a afetar também aos brancos, diferente parece ter sido a sorte destes no desfeito do processo, com respeito à situação dos escravos. Nos documentos consultados, brancos - como Inácio Siqueira e sua filha - mesmo sendo condenados recorreram da sentença e pouco tempo depois estavam em liberdade. ${ }^{14}$ Algo similar parece ter acontecido com Manoel da Silva Carrier, que teve seu livramento declarado no mesmo termo da condena à prisão. ${ }^{15} \mathrm{O}$ pagamento das taxas e da tramitação do processo,

9. ACMSP, Processo de Feitiçaria para Matar Gente, Pascoa, 1749

10. Laura de Mello e Souza, op. cit., p. 197.

11. Ibid., p. 194.

12. ACMSP, Processo de Livramento, Inácio de Siqueira, 1772.

13. ACMSP, Processo de Auto de Culpa, Manoel da Silva Carrier, 1759.

14. ACMSP, Processo de Livramento, Inácio Siqueira, 1772.

15. ACMSP, Processo de Auto de Culpa, Manoel da Silva Carrier, 1759. 
que não era pouco, teria facilitado o livramento.

Toda esta magnanimidade não foi aplicada no caso dos escravos. O já mencionado Patrício Bicudo da Silva, mulato e escravo acusado de feitiçaria por ensinar remédios caseiros e rezas para curar mordidas da cobra, foi condenado à prisão. Não foram considerados todos os testemunhos apresentados a seu favor, nos quais aparece como alguém interessado em exercer a caridade com quem estava sofrendo. Pelo processo, o ciúme do denunciante, seu próprio senhor, teve mais peso ante o juiz, que as testemunhas. Ainda, sua condição de escravo, parece ter inflúdo para que a oferta de pagamento por sua liberdade, que seus amigos ofereceram, não fosse aceita. ${ }^{16}$ Ao contrário dos brancos, que apelaram com sucesso da sentença, a petição dos amigos de Patrício contestava a rigidês das normas do regime escravista. Como de costume, este estava pouco interessado em tolerar as provas de solidariedade dos livres com um simples escravo, que pelas suas ações humanitárias alcançava a dignidade que sua condição lhe negava.

Pe. Antônio Raimundo Pereira de
Jesus é mestrando em História da
Evangelização na América Latina.
Endereço:
Caixa Postal 297
CEP 1702$\}-970$ - Bauru - SP.

\section{COTIDIANO PAROQUIAL E LIVROS DE TOMBO}

Fernando Torres Londoño

A

o considerar a importância conferida à paróquia para a vida da Igreja pelo Documento de Santo Domingo e tendo em mente a situação atual das paróquias no Brasil, não deixa de apresentar-se para o historiador e mesmo para os pastores e os agentes de pastoral a pergunta pelo passado mais longínqüo da paróquia no Brasil. Como eram as nossas paróquias no período colonial? Que diferenças e que semelhanças pode apresentar o cotidiano das freguesias em quase 500 anos de história da Igreja no Brasil? Porém, surgindo a pergunta, não é fácil que apareça a resposta.

Além de inúmeras páginas e poucos trabalhos, carecemos de estudos que resgatem o cotidiano de fregueses e freguesias no passado. As fontes se contam entre as difi- culdades encontradas para reconstituir a história da base da Igreja. Dispersas e com lacunas, as fontes não ajudam para o resgate do universo paroquial. Os "Livros de Tombo" aparecem como uma passagem para esse universo que em alguns traços pode seguir sendo atual. Os 10 "Livros de Tombo" do período colonial e do século XIX que existem no Arquivo da Cúria Metropolitana de São Paulo, são uma mostra do que esta documentação pode representar para o historiador. No século XVIII as Constituições Primeiras do Arcebispado da Bahia, se pronunciaram em vários numerais com respeito aos diversos livros de registro que deveriam existir nas paróquias: de batismos, de matrimônios, de óbitos, de matrículas de ordens. Entre eles se mencionam ainda dois: um " $l i$ vro de Igreja" onde deveriam ser registrados os ornamentos e mó- 